\title{
INVESTIGAÇÕES SOBRE O VENTO NORTE NA REGIÃO CENTRAL DO RIO GRANDE DO SUL UTILIZANDO UMA MICRO-REDE DE ESTAÇÕES METEOROLÓGICAS
}

Amanda Rehbein, Otávio C. Acevedo, Pablo E. S. Oliveira, Hans R. Zimmerman, Guilherme M. Silva

Universidade Federal de Santa Maria

\section{RESUMO}

$\mathrm{O}$ vento norte, um fenômeno caracterizado por ventos de forte intensidade na região central do estado do Rio Grande do Sul, Brasil, foi investigado usando dados de uma micro-rede de estações meteorológicas.

\begin{abstract}
The North Wind, a phenomenon characterized by intense winds in the central region of Rio Grande do Sul state, Brazil, was investigated using data from a meteorological stations' micro-web.
\end{abstract}

\section{INTRODUÇÃO}

A região central do estado do Rio Grande do Sul (RS), Brasil, é afetada pela ocorrência de um fenômeno conhecido localmente como Vento Norte (VN). Esse é caracterizado por ventos de forte intensidade durante várias horas até alguns dias vindos de norte, noroeste ou nordeste, promovendo aumento abrupto da temperatura do ar em baixos níveis e diminuição da umidade relativa. Esses episódios de VN normalmente precedem a aproximação de uma perturbação sinótica migratória sobre o RS (CHAMIS e NASCIMENTO, 2012).

Chamis e Nascimento $(2011$; 2012) mostraram que nem todos os casos de tempestade de ventos fortes vindos de norte caracterizam episódios de $\mathrm{VN}$, pois para isso precisa-se observar um acentuado aumento de temperatura durante a ocorrência desses. Um experimento de campo foi iniciado em agosto de 2012 para investigar o fenômeno. Buscouse verificar sua duração, horário de início e fim em estações distribuídas espacialmente na região de Santa Maria e dois municípios próximos, bem como a temperatura média associada a cada evento em cada estação.

\section{MATERIAIS E MÉTODOS}

Os dados utilizados foram coletados por uma micro-rede de estações meteorológicas pertencente ao projeto "Micro-rede de observações meteorológicas no Sul do Brasil" do Laboratório de Micrometeorologia da UFSM. Sete estações registraram dados a cada 2 minutos, de agosto de 2012 a março de 2013, totalizando 200 dias de observação. As estações Itaara (alto da serra), declive (próximo ao topo da serra), base da serra, Santa Maria e Santa Flora foram instaladas seguindo uma linha perpendicular ao gradiente topográfico. Deste modo, a variação de altitude entre essas estações chega a mais de $300 \mathrm{~m}$ desde o ponto mais alto (Itaara) até o mais baixo (Santa Maria). A estação de São Pedro do Sul foi instalada 
a oeste e a de São João do Polêsine a leste das anteriores, com o objetivo de se identificar o alcance longitudinal do fenômeno.

Seguindo Chamis e Nascimento $(2011,2012)$. foi considerado um episódio quando a direção do vento esteve entre $315^{\circ}$ e $45^{\circ}$ por mais de 4 horas consecutivas em todas as estações, seguidas pelo aumento de temperatura.

\section{RESULTADOS E DISCUSSÕES}

A Tabela 1 traz o início de cada episódio de $\mathrm{VN}$ por estação. $\mathrm{O}$ zero indica a primeira estação a registrar VN. As demais numerações são a diferença do horário do início de VN nas demais estações. No declive e base da serra, observa-se a predominância no início do fenômeno. Já a estação de Santa Flora apresenta o início de VN mais tardio de todas as estações seguido pela de Santa Maria, evidentemente por estarem localizadas no extremo sul da micro-rede. Na Tabela 2, estão as relações de término de VN por episódio por estação.

O início do vento norte em São Pedro do Sul foi anterior ao de São João do Polêsine na maioria dos casos. Isso mostra que há uma predominância do vento de se deslocar de noroeste para sudeste.

Os episódios de VN em cada estação tendem a terminar em horários mais próximos do que quando iniciam. Isso pode estar relacionado com o estabelecimento do sistema sinótico sobre a região, que causa uma abrupta mudança de tempo.

Verificou-se que os episódios de VN tem início preferencial nas primeiras horas da manhã e término nas primeiras horas da tarde, em concordância com Chamis e Nascimento (2012).

\begin{tabular}{lccccccccc} 
Tabela & $\mathbf{1}$ & - & \multicolumn{3}{c}{ Hora } & \multicolumn{3}{c}{ inicial } & \multicolumn{2}{c}{ dos } \\
\hline & $23-24$ & $14-18$ & $13-17$ & $22-24$ & $8-10$ & $4-7$ & $18-20$ & $23-26$ \\
Estação & Ago & Set & Out & Out & Nov & Dez & Dez & Dez \\
\hline Itaara & 0 & 9 & 12 & 12 & 2 & 2 & 2 & 2 \\
Declive & 0 & 0 & 36 & 0 & 6 & 0 & 0 & 0 \\
Base & $5^{1}$ & 12 & 0 & 6 & 0 & 0 & 3 & 24 \\
Santa Maria & $0^{1}$ & $57^{1}$ & 24 & 12 & 21 & 9 & 13 & 24 \\
Santa Flora & $5^{1}$ & 21 & 72 & 21 & 10 & 12 & 18 & 24 \\
São Pedro & 2 & 12 & 21 & 0 & 10 & 21 & 13 & 24 \\
Polêsine & 2 & 42 & 54 & 9 & 9 & 12 & 12 & 21 \\
\hline
\end{tabular}

Tabela 2 - Hora final dos episódios de vento norte.

\begin{tabular}{lcccccccc}
\hline & $23-24$ & $14-18$ & $13-17$ & $22-24$ & $8-10$ & $4-7$ & $18-20$ & $23-26$ \\
Estação & Ago & Set & Out & Out & Nov & Dez & Dez & Dez \\
\hline Itaara & 0 & 17 & 24 & 6 & 2 & 2 & 2 & 2 \\
Declive & 0 & 17 & 24 & 0 & 0 & 0 & 0 & 6 \\
Base & 0 & 0 & 0 & 3 & 0 & 0 & 18 & 3 \\
Santa Maria & 0 & $2^{1}$ & 3 & $0^{1}$ & 0 & 3 & 0 & 3 \\
Santa Flora & 0 & $0^{1}$ & $24^{1}$ & 15 & 2 & 3,5 & 0 & 2 \\
São Pedro & 2 & 2 & 0 & 6 & 0 & 9 & 47 & 3 \\
Polesine & 2 & 5 & 24 & 3 & 2 & 0 & $6^{1}$ & 0 \\
\hline
\end{tabular}

${ }^{1}$ Falha nos dados; ${ }^{2}$ Estação inoperante.

\section{CONCLUSÕES}

Apesar do período analisado não compreender a época preferencial para a ocorrência do fenômeno, algumas conclusões podem ser tomadas, tais como a predominância no avanço do 
VN sobre a região a partir do noroeste e os episódios de VN possuírem início nas primeiras horas da manhã e término nas primeiras horas da tarde.

\section{BIBLIOGRAFIA}

CHAMIS, M. L.; NASCIMENTO, E. L. Condições atmosféricas associadas a episódios de "Vento Norte" na região central do Rio Grande do Sul. Anais do XVII Congresso Brasileiro de Meteorologia, Gramado - RS, 2012.

CHAMIS, M. L.; NASCIMENTO, E. L. Estudo de episódios de "Vento Norte" no Rio Grande do Sul por um ponto de vista sinótico. Anais do IV Encontro Sul Brasileiro de Meteorologia, Pelotas - RS, 2011. 